\title{
Colon angiolipoma with intussusception: a case report and literature review
}

\author{
Lei Wang, Ping Chen*, Liang Zong, Guang-Yao Wang and Hao Wang
}

\begin{abstract}
Angiolipomas are frequently observed benign tumors. They have a typical vascular component and are often located in subcutaneous tissues, and more rarely, in the gastrointestinal tract. We present the case of a 58-year-old man who complained of abdominal discomfort in the left lower quadrant and two to three bloody stools a day without any obvious etiology. These symptom became more severe in the next three days, due to a large angiolipoma located in the descending colon, which was diagnosed intraoperatively. In a literature review, we found only 22 cases of angiolipomas involving the gastrointestinal tract which are reported in the literature from 1960 to 2012 in PubMed; the key words used in the search are gastrointestinal tract angiolipoma, esophagus, stomach, duodenum, intestine, ileocecal junction, colon, rectum angiolipomas. Colon angiolipoma with intussusception, as seen in this case, is rare and may require emergent surgical intervention.
\end{abstract}

Keywords: Gastrointestinal tract angiolipoma, Colon angiolipoma, Intussusception, Colon cancer

\section{Background}

Angiolipoma is a benign tumor, commonly occurring in the subcutaneous tissue and other locations, but is rarely found in the gastrointestinal tract. Histologically, it is comprised of adipose tissue and proliferative blood vessels and is usually diagnosed postoperatively. This report focuses on the importance of correct pre- and/or intraoperative histological diagnosis in order to offer the best therapeutic choice with the diagnosis confirmed postoperatively.

\section{Case presentation}

A 58-year-old male patient was admitted to $\mathrm{Su}$ Bei People's Hospital of Jiangsu Province on 13 March 2012, with a major complaint of 'lower left quadrant abdominal discomfort with bloody stools.' His symptoms began about a month prior to the abdominal discomfort in the lower left quadrant and he experienced two to three bloody bowel movements a day without an obvious etiology. These symptoms became more severe in the next three days. Blood appeared purple and red on the surface of soft stools combined with mucus. He also experienced occasional abdominal pain and tenesmus.

\footnotetext{
*Correspondence: chen86ky@126.com

Department of Gastrointestinal Surgery, Su Bei People's Hospital of Jiangsu Province, Yangzhou University, Yangzhou 225001, Jiangsu Province, China
}

Colonoscopy (Figure 1) at an outside hospital on 5 March 2012 had revealed a large pedunculated, cauliflower shaped lump with superficial ulceration and necrosis at approximately $40 \mathrm{~cm}$ from the anal verge. The mass appeared hard and friable. The rest of the colon and rectum appeared normal. Biopsy of the lesion showed non-specific chronic mucosal inflammation with necrosis and exudate. The patient's past medical history and family history were unremarkable. At his physical examination on arrival at our hospital, the abdomen was soft, non-distended and without visible peristalsis. There was mild tenderness on palpation without rebound tenderness. No lumps were spotted. Rectal examination was unremarkable and blood was present. Laboratory tests showed a white blood cell count of $7.4 \times 10^{9} / \mathrm{L}$, a red blood cell count of $3.08 \times 10^{12} / \mathrm{L}$, a neutrophil count of $5.78 \times 10^{9} / \mathrm{L}(78.1 \%)$, and a hemoglobin level of $90 \mathrm{~g} / \mathrm{L}$. Tumor markers were as follows: alpha fetoprotein (AFP) 3.87, CA 199, and carcinoembryonic antigen (CEA) 2.29. An abdominal CT scan with contrast showed a $5-\mathrm{cm}$ diameter lump-like lesion at the junction of the descending and sigmoid colon with significantly thickened walls with dilated lumen (Figure 2). There were multiple rings within the lump with smooth rims suggesting colon intussusception. Colon cancer could not be ruled out. The patient was urgently taken to the 


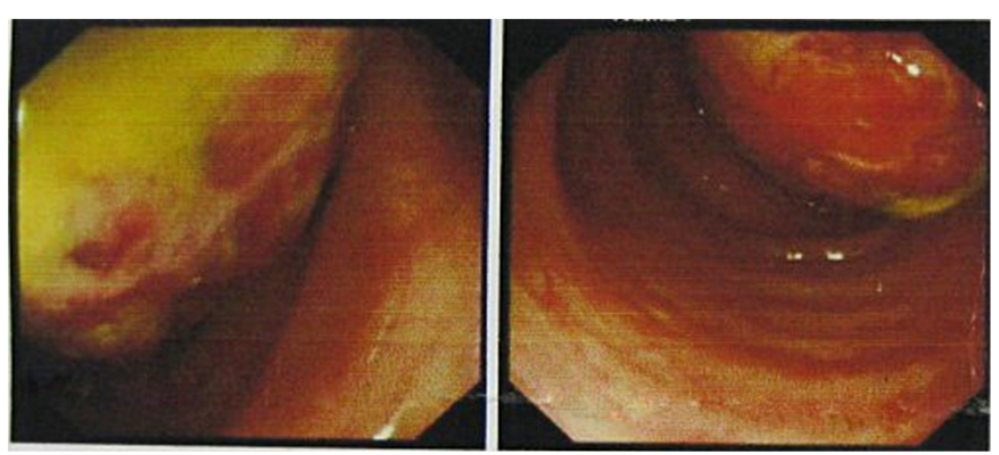

Figure 1 Colonoscopy revealed a large pedunculated, cauliflower shaped mass with superficial ulceration and necrosis at approximately $40 \mathrm{~cm}$ from the anal verge. The mass appeared hard to the touch and friable.

operating room to probe with a preoperative diagnosis of colon intussusception and possible colon cancer. Intraoperatively, the mass was located at the splenic flexure measuring $10 \times 7 \mathrm{~cm}$. Colon intussusception was present with dilatation of the proximal colon. No other lesions were identified. Once the intussusception was reduced, an $8 \times 5 \mathrm{~cm}$ colon lesion was revealed and a partial colectomy was performed. Frozen section revealed an angiolipoma. No further resection was indicated. The patient recovered from surgery well and was taken back to the ward. Final pathology showed an $8 \times 6 \times$ $6 \mathrm{~cm}$ exophytic colon lesion consisting mainly of fatty tissue with ulceration. Seven lymph nodes ranging from $2 \mathrm{~mm}$ to $10 \mathrm{~mm}$ were identified outside the colon. Histologic examination (Figure 3) revealed a mass consisting of mature adipose tissue with vascular structures. Intralesional fat necrosis and mucosal ulcerations were present with a large amount of neutrophil and lymphocyte infiltration. Lymph nodes showed reactive proliferation with no evidence of tumor. The final pathologic diagnosis was angiolipoma of the descending colon. During follow-up, this patient showed no recurrence.

\section{Discussion}

Angiolipoma was first described in 1912 by Bowen [1]. In 1960, Howard [2] demonstrated that the clinicopathological features of angiolipomas differed from those of lipomas, thereby delineating angiolipoma as a new entity. It can be classified by the ratio of adipose and vascular tissue composition as predominantly lipomatous or angiomatous type [3]. Cytogenetic analysis shows the normal karyotype of angiolipomas contrasts with the various other types of benign lipomatous tumors, most of which show rather specific clonal chromosomal aberrations [4], which suggests that the pathogenesis of angiolipomas may be different from that of ordinary lipomas. Angiolipomas usually develop as encapsulated subcutaneous tumors, most commonly on the arms and trunk in young adults. They are rarely larger than $2 \mathrm{~cm}$ in diameter, frequently multiple in number and characteristically tender or painful [5]. They are rarely found in the gastrointestinal tract. In a literature review, we found only 22 cases of angiolipomas involving the gastrointestinal tract. Of these, one was located in the esophagus [6], three in the stomach [7-9], two in the duodenum $[10,11]$, six in the small intestine [12-17], three at the ileocecal junction [18-20], five in the colon [3,10,21-23], and two in the rectum [24,25]. Angiolipomas in the gastrointestinal tract usually do not have specific clinical manifestations. Patients are often asymptomatic when the tumor is small. With increasing size of the tumor, they may experience abdominal pain, abdominal distension, melena, and symptoms of intussusception and bowel obstruction. Colon angiolipoma with intussusception, as seen in this case, is rare and may require urgent surgical intervention. Only two such cases have been reported in the literature $[23,26]$.

Radiological examination including barium radiographs, enteroclysis, abdominal ultrasound, computed tomography (CT), and magnetic resonance imaging (MRI) can detect the lesion in the gastrointestinal tract before histopathological diagnosis. Barium enema [3] and enteroclysis [17] may show a filling-defect in the lumen which usually appears as a hyperechoic lesion on transabdominal ultrasonography $[3,16]$ and a submucosal lesion in the gastrointestinal wall in endosonography [6] with central high signal intensity and peripheral isosignal intensity on T1-weighted inphase images [17]. CT image characteristics depend on the tissue composition of the lesion, from a lipomatous type comprised of fat without contrast enhancement, which is often diagnosed as a lipoma [27], to a low-fat containing tumor showing numerous small round density enhancements [28,29]. In 1998, Mintz and Mengoni [30] reported the use of sonography to diagnose a breast angiolipoma, which appeared as a homogeneously hyperechoic density on echogram. Chen et al. [3] also reported the successful use of imaging to diagnose an angiolipoma that was later 

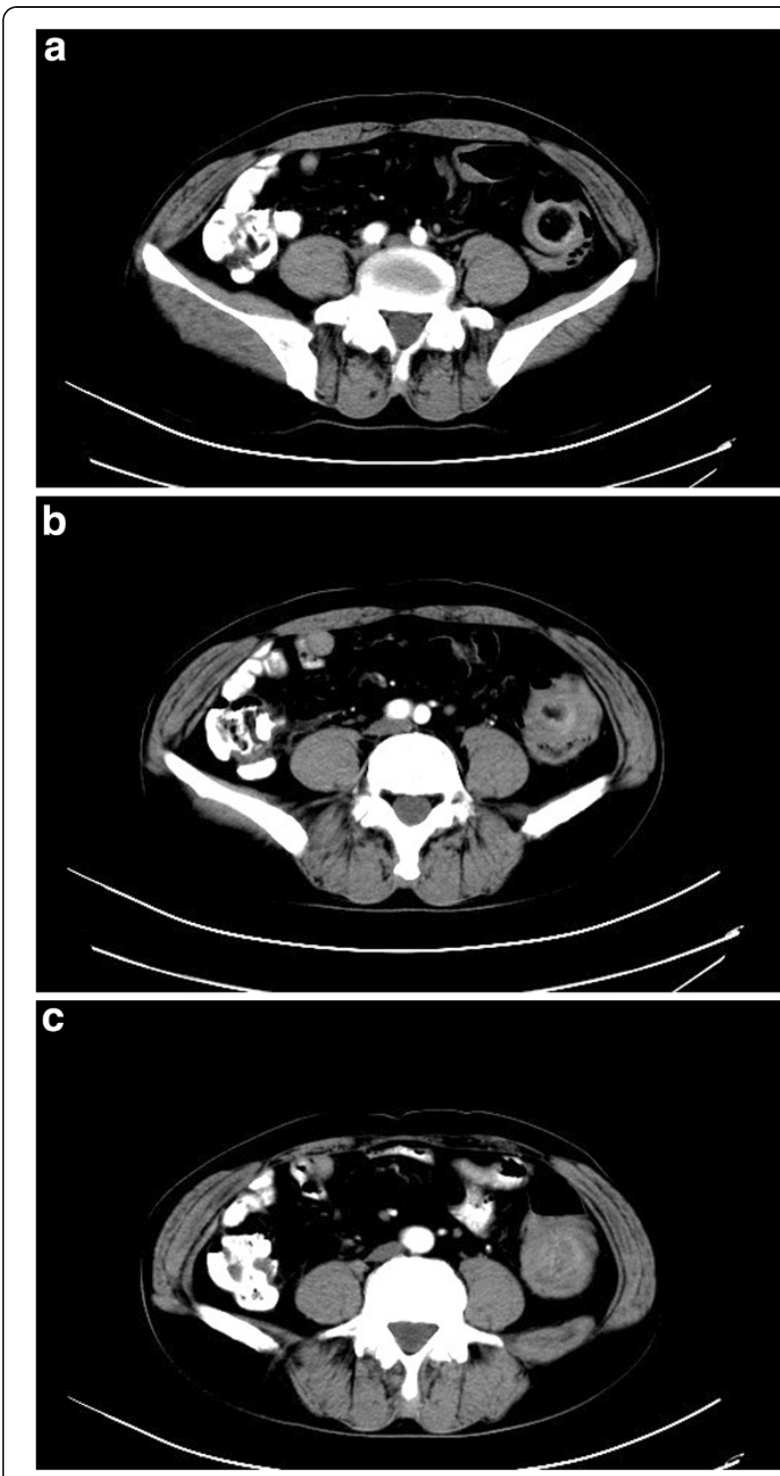

Figure 2 Abdominal CT scan with contrast from (a) to (c) showed a $5 \mathrm{~cm}$ diameter mass-like lesion at the junction of the descending and sigmoid colon with significantly thickened walls with dilated lumen. There were multiple rings within the mass with smooth margins suggesting colon intussusception. $C T$, computed tomography.

confirmed with surgical pathology. However, the overall pre-operative diagnostic accuracy for gastrointestinal angiolipomas is quite low due to the non-specific clinical presentations and lack of specific findings on imaging studies. Error in diagnosis can lead to inappropriate surgery such as an unnecessary radical resection because of an erroneous preoperative diagnosis of colon cancer. The correct diagnosis of gastrointestinal angiolipomas is usually made intraoperatively and confirmed by final surgical pathology. When possible, an intraoperative biopsy with frozen section may provide an accurate diagnosis to guide surgery. In our case, preoperative biopsy during colonoscopy only showed non-specific inflammation without tumor cells. Combined with the CT findings, we doubted the presence of colon cancer and elected to obtain intraoperative frozen sections, which indeed revealed a benign process, thus avoiding an unnecessary radical resection.

The treatment options for colon angiolipoma vary depending on the type of lesions. Small pedunculated polyps can be removed under colonoscopy. Injection of epinephrine,and the use of nylon loop or metal hemostatic clips prior to polypectomy may effectively decrease intraoperative bleeding $[10,22]$. For large lesions or broad-based polyps, surgical excision is the treatment of choice. Compared to endoscopic excision, surgical resection may reduce the risk of perforation and hemorrhage in these patients [3]. However, minimally invasive procedures such as laparoscopic resection may be possible. Vandamme et al. [21] reported a case of cecal angiolipoma that was successfully treated with laparoscopy-assisted ileocecostomy and a five-year follow-up showed no recurrence. Ishizuka et al. [25] successfully treated a rectal angiolipoma through a transanal approach. Open surgical resection was chosen for our patient due to the large size of the tumor $(8 \times 6 \times$

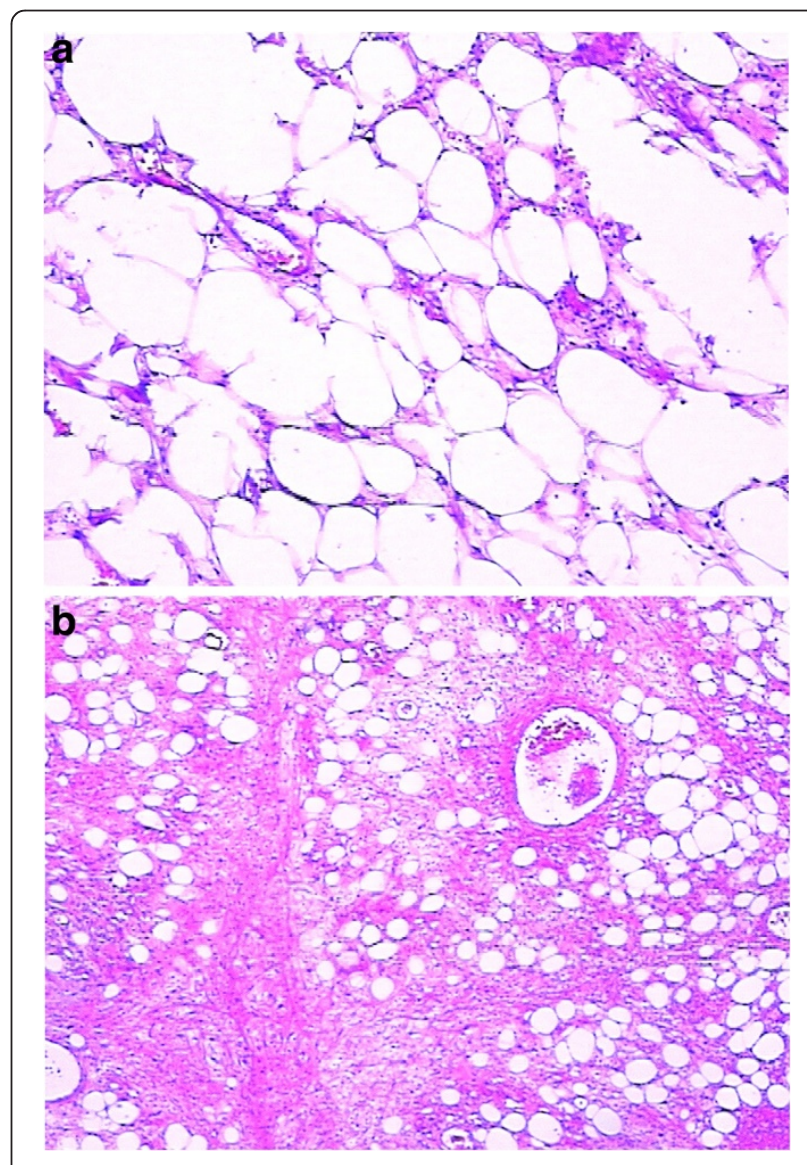

Figure 3 Histologic examination from (a) and (b) revealed a mass consisting of mature adipose tissue with vascular structures. 
$6 \mathrm{~cm})$ and evidence of colon intussusception which required urgent examination. Because angiolipomas are benign tumors, only limited colon resection should be performed provided that the tumor can be completely removed $[19,22]$. Studies have shown $[12,25]$ that excellent prognosis can be expected with complete tumor removal although recurrence is high when the tumor is inadequately resected.

\section{Conclusion}

Angiolipoma is a benign tumor, commonly occurring in the subcutaneous tissue and is rarely found in the gastrointestinal tract. Error in diagnosis can lead to inappropriate surgery such as an unnecessary radical resection because of an erroneous preoperative diagnosis of colon cancer. We should focuses on the importance of correct pre- and/or intraoperative histological diagnosis in order to offer the best therapeutic choice.

\section{Consent}

Written informed consent was obtained from the patient for publication of this case report and any accompanying images.

\section{Competing interests}

The authors declare that they have no competing interests.

\section{Authors' contributions}

$\mathrm{WL}$ and CP performed the majority of this study and wrote the manuscript; ZL, WGY and WH provided the collection of material from the database. All authors read and approved the final manuscript.

Received: 15 September 2012 Accepted: 23 February 2013

Published: 15 March 2013

\section{References}

1. Bowen JT: Multiple subcutaneous hemangiomas, together with multiple lipomas, occurring in enormous numbers in an otherwise healthy, muscular subject. Am J Med Sci 1912, 144:189-192.

2. Howard WR, Helwig EB: Angiolipoma. Arch Dermatol 1960, 82:924-931.

3. Chen YY, Soon MS: Preoperative diagnosis of colonic angiolipoma: a case report. World J Gastroenterol 2005, 11:5087-5089.

4. Sciot R, Akerman M, Clin P, De Wever I, Fletcher CD, Mandahl N, Mertens F, Mitelman F, Rosai J, Rydholm A, Tallini G, Van den Berghe H, Vanni R, Willen $\mathrm{H}$ : Cytogenetic analysis of subcutaneous angiolipoma: further evidence supporting its difference from ordinary pure lipomas: a report of the CHAMP study group. Am J Surg Pathol 1997, 21:441-444.

5. Rogy MA, Mirza D, Berlakovich G, Winkelbauer F, Rauhs R: Submucous large-bowel lipomas: presentation and management. An 18-year study. Eur J Surg 1991, 157:51-55.

6. Jensen EH, KlaPman JB, Kelley ST: Angiolipoma of the esophagus: a rare clinical dilemma. Dis Esophagus 2006, 19:203-207.

7. DeRidder PH, Levine AJ, Katta JJ, Catto JA: Angiolipoma of the stomach as a cause of chronic upper gastrointestinal bleeding. Surg Endosc 1989, 3:106-108.

8. McGregor DH, Kerley SW, McGregor MS: Case report: gastric angiolipoma with chronic hemorrhage and severe anemia. Am J Med Sci 1993, 305:229-235.

9. Hunt J, Tindal D: Solitary gastric Peutz-Jeghers Polyp and angiolipoma presenting as acute haemorrhage. Aust N Z J Surg 1996, 66:713-715.

10. Mohl W, Fischinger J, Moser C, Remberger K, Zeuzem S, Stallmach A Duodenal angiolipoma-endoscopic diagnosis and therapy. Z Gastroenterol 2004, 42:1381-1383.

11. Jung IS, Jang JY, Ryu CB, Hong SJ, Kim JO, Cho JY, Lee JS, Ms L, Jin SY, Shim CS, Kim BS: Angiolipoma of duodenum diagnosed after endoscopic resection. Endoscopy 2004, 36:375.
12. Della Volpe N, Bianco L, Bonuso C, Annecchiarico M, Di Silverio P, Caiazza A: Rare ileal localisation of angiolipoma presenting as chronic haemorrhage and severe anaemia: a case report. J Med Case Rep 2008, 29:129.

13. Aminian A, Noaparast M, Mirsharifi R, Bodaghabadi M, Mardany O, Ali FA, Karimian F, Toolabi K: lleal intussusception secondary to both lipoma and angiolipoma: a case report. Cases J 2009, 2:7099.

14. Ferrozzi F, Rubino S, Uccelli M: lleal angiolipoma in a patient with multisystemic manifestations of tuberous sclerosis: diagnosis with computerized tomography. Radiol Med 1998, 96:403-405.

15. Kaneko T, Karasawa $Y$, Inada H, Tamura Y, Yamamura N, lijima $Y$, Nagata A, Oohata T, Shirota H, Nakamura T, Hara E: An adult case of intussusception due to inverted Meckel's diverticulum accompanied by angiolipoma. Nihon Shokakibyo Gakkai Zasshi 1996, 93:260-265.

16. Manner M, Scholz E, Wehrmann M, Stickel W: Invagination caused by angiolipoma of the small intestine-a rare cause of occult gastrointestinal hemorrhage. Chirurg 2001, 72:305-307.

17. Kwak HS, Kim CS, Lee JM: Small intestine angiolipoma: MR imaging appearance. Abdom Imaging 2003, 28:515-517.

18. Aouad K, Texier P, Bloch F, De Labriolle-Vaylet C, Bouillot JL: Benign angiolipoma of the Bauhin valve causing severe digestive tract bleeding. Gastroenterol Clin Biol 2000, 24:686-688.

19. Kato K, Matsuda M, Onodera K, Sakata H, Kobayashi T, Kasai S: Angiolipoma of the colon with right lower quadrant abdominal pain. Dig Surg 1996, 16:441-444.

20. Saroglia G, Coverlizza S, Roatta L, Leli R, Fontana D: Angiolipoma of the cecum. Minerva Chir 1996, 51:59-62.

21. Vandamme J: Angiolipoma of the colon. Acta Gastroenterol Belg 1964, 27:750-757

22. Okuyama T, Yoshida M, Watanabe M, Kinoshita Y, Harada Y: Angiolipoma of the colon diagnosed after endoscopic resection. Gastrointest Endosc 2002, 55:748-750.

23. Lu PH, Wei-Shen L-J: Umbilical region pain, diarrhea, and bloody stools Angiolipoma of the gastrointestinal tract. Gastroenterology 2011, 140:e1-e2. doi:10.1053/j.gastro.2009.12.078.

24. Kacar S, Kuran S, Temucin T, Odemis B, Karadeniz N, Sasmaz N: Rectal angiolipoma: a case report and review of literature. World J Gastroenterol 2007, 13:1460-1465.

25. Ishizuka M, Nagata H, Takagi K, Horie T, Abe A, Kubota K: Rectal angiolipoma diagnosed after surgical resection: a case report. World $\lrcorner$ Gastroenterol 2007, 13:467-469.

26. Grasso E, Guastella T: Giant submucosal lipoma cause colo-colonic intussusception a case report and review of literature. Ann Ital Chir 2012, 83:559-562.

27. Ferrozzi F, Tognini G, Bova D, Pavone P: Lipomatous tumors of the stomach: CT findings and differential diagnosis. J Comput Assist Tomogr 2002, 24:854-858.

28. Biondetti PR, Fiore D, Perin B, Ravasimi R: Infiltrative angiolipoma of the thoracoabdominal wall. J Comput Assist Tomogr 1982, 6:847.

29. Pfeil SA, Weuver MG, Abdul-Karim FW, Yang P: Colonic lipomas: outcome of endoscopic removal. Gastrointest Endosc 1990, 36:435-438.

30. Mintz AD, Mengoni P: Angiolipoma of the breast: sonographic appearance of two cases. J Ultrasound Med 1998, 17:67-69.

\section{doi:10.1186/1477-7819-11-69}

Cite this article as: Wang et al:: Colon angiolipoma with intussusception: a case report and literature review. World Journal of Surgical Oncology 2013 11:69. 